\title{
Use of spectral analysis for detection of alterations in ETM data, Yazd, Iran
}

\author{
Rashed Poormirzaee • Majid Mohammady Oskouei
}

Received: 22 November 2009 / Accepted: 27 June 2010 /Published online: 13 August 2010

(C) The Author(s) 2010. This article is published with open access at Springerlink.com

\begin{abstract}
Spectral analysis methods were used for detection of mineralogical features on a set of Enhanced Thematic Mapper Plus data of Behabad zone, central Iran. Several indicative minerals for hydrothermal alterations were identified in the study area. The spectra of unknowns were determined by comparing to USGS mineral spectral library. Different pre-processings and processings were performed to achieve the highest possible accuracy. These are the minimum noise fraction, the pixel purity index analysis, spectral feature fitting, spectral angle mapper and binary encoding. The results of spectral analysis, as a map of minerals abundances, along with the results of other Image processing methods such as least square fit, and Crosta method were integrated within ArcGIS Software to achive a potential map of hydrothermal alterations. The minerals: allanite, magnetite, alunite, clay minerals, and muscovite were therefore detected and mapped in this study. The detected alterations here highly match to the mineral concentrations which are formerly found and measured in the study area that emphasizes the reliability of the applied method.
\end{abstract}

Keywords Remote sensing · GIS · Spectral analysis .

Multispectral analysis $\cdot$ Mineral detection

Alteration mapping

\section{Introduction}

A diversity of previous researches has proved the reliability of multispectral data analysis in the field of alteration

R. Poormirzaee $(\bowtie) \cdot$ M. M. Oskouei

Sahand University of Technology,

Tabriz, Iran

e-mail: Rashed.poormirzaee@gmail.com detection. Among them, Landsat data are important because of their broad coverage and popularity. On the other hand, Improvements in design of sensors and precise spectrometers helped researchers to measure different laboratory spectra. This advances spectral analysis as a quantitative method for applied remote sensing.

The foundation for quantitative analysis of remote sensing data through spectral analysis is reflectance spectroscopy.

Reflectance is generally defined as the ratio of the intensity of the electromagnetic radiation scattered from a surface to the intensity of the radiation incident upon it. When measured as a function of wavelength, reflectance spectra exhibit specific albedo, continuum, and absorption features which are a function of material properties of the surface measured. The absorption features are related to the chemical composition and mineralogy of the surface, while the continuum and overall albedo are a function of nonselective absorption and scattering as well as broad wavelength selective absorption (Rencz 1999).

Spectral analysis, one of the most advanced remote sensing techniques, were used as a possible means of identifying the mineralogy of the clay fractions in the Kuchuk, Izmir, Turkey. Different spectral processes were used to execute the prospective spectral analyses (Altinbas et al. 2005).

Spectroscopy by satellite images has many new and exciting applications. Areas such as agriculture, forestry, geology and many others have great potential for new research advances using this technology (Islam et al. 2004)

Economic mineralization is often occurred by fluid processes that substantially alter the mineralogy and chemistry of the host rocks. This alteration can produce distinctive assemblages of minerals that vary according to the location, degree and longevity of those flow processes. When exposed to the surface of the Earth this alteration can sometimes be mapped at a zonal pattern (Ferrier et al. 2001). By using 
remote sensing techniques, these zones can be detected in a regional scale.

This study aims to detect and map alterations indicated by mineral such as allanite, magnetite, jarosite, goethite, clay minerals and muscovite using spectral analysis. Least square fit (LS-Fit) and Crosta methods were also performed to achieve better accuracy along with spectral analysis.

The outcomes of above mentioned methods were integrated in ArcGIS Software to verify the accuracy of the results using the formerly done field observations. The high coinciding to the places of the measured mineral concentrations illuminates the potential of Enhanced Thematic Mapper Plus (ETM+) satellite imagery data to map spectral signatures associated with the hydrothermal alterations.

\section{Geology of study area}

The study area (the Behabad zone) is located in the province of Yazd, east of Yazd city and in the central Iranian continental terrains, as part of the larger Alpine-Himalayan orogenic system. It is located between $56^{\circ} 00^{\prime}$ and $56^{\circ} 30^{\prime} \mathrm{E}$ and between $31^{\circ} 30^{\prime}$ and $32^{\circ} 00^{\prime} \mathrm{N}$. This zone is extended from Poshte-Badam block in the west to the Tabas block in the east exposing a faulted facies like them. The Behabad covered by cenozoic alluvial including interbeddings of thin clay and salts.

ETM+ imagery data

The launch of Landsat 7 on April 15, 1999 continued the series of moderate resolution. The ETM+ sensor is the imaging payload on the Landsat 7 spacecraft. It uses the whiskbroom scanner architecture common to the Thematic Mapper (TM) sensor family, also flown on Landsats 4 and 5, with several evolutionary refinements including the addition of a 15-meter resolution panchromatic band and a higher resolution $(60 \mathrm{~m})$ thermal band (Markham et al. 2008). One of the improvements of the ETM+ instrument over the previous TM one, for enhancing radiometric precision, and consequently for better land-cover discrimination, is its capability to scan in either a low or highgain state. Gain is denoted as an increase in signal power during its transmission from one point to another in order to maximize the radiometric resolution ( 8 bits in the case of the $\mathrm{ETM}+$ ) without saturating the detectors (whose digital number (DN) maximum is 255) (Karnieli et al. 2004).

\section{Methods}

Applying preprocessing is necessary for image processing, clarity improving of image, and removing of some systematically errors. Preprocessing requires to prepare high quality data for analysis purposes then performed on data(Oskouei and Busch 2008).
To this end, at the beginning of the path, radiance correlation by ENVI4.2 software which is essential for multispectral images, was implemented. Then, principal component analysis transform (PCA) was applied to estimating the virtual dimensionality in order to reduce the data volume and also minimum noise fraction (MNF) to separate the noise and signal in data. Different classes or endmembers were then determined by $n$-dimensional visualizer and the minerals having best match to the spectra of endmembers were distinguished using spectral feature fitting (SFF) by comparing with the USGS mineral spectral library. The results of LS-Fit and Crosta methods were used for better recognition of alterations in the region as well. Five minerals were successfully identified in the study area. The outcomes of above mentioned processing were integrated in ArcGIS desktop as data layers to achieve a comprehensive potential map for the study area.

\section{LS-Fit method}

Both LS-Fit and Crosta methods were used to map spectral signatures of hydrothermal alterations (i.e. clay minerals and iron oxides). LS-Fit method performs a linear band prediction using a least squares fitting technique. It is used to find regions of anomalous spectral response (e.g. altered clay minerals and Iron oxides) in a data set. It calculates the covariance of the input data and uses it to predict the selected band as a linear combination of the predictor bands (Haroni and Lavafan 2007) (Fig. 2).

Figure 1 illustrates an output image of the LS-Fit model indicating the distribution of clay alterations as dark pixels. This map was created by using all the six visible and short wave infrared bands as the input and band 7 as the modelled band. This method was applied to find the Fe-oxidations, because it is usually associated with hydrothermal alteration. In this case, since the ferrous $\mathrm{Fe}$ oxides show an absorption feature across band 3, this band was therefore used as a model band to map iron oxides (Haroni and Lavafan 2007).

In this part, we mapped hematite, clay and goethite by using residual band 3 , residual band 7 and residual band 1 (Fig. 3). The dark pixels indicate abovementioned minerals in these images (Yetkin et al. 2004).

Here, it is important to use visible and IR bands to calculate the residuals of these bands.

\section{Crosta method}

The PCA is a multivariate statistical technique that selects uncorrelated linear combinations (eigenvector loadings) of variables in such a way that each successively extracted linear combination or principal component (PC) has a smaller variance (Singh and Harrison 1985). The main aim of PC analysis is to remove redundancy in multispectral data. 


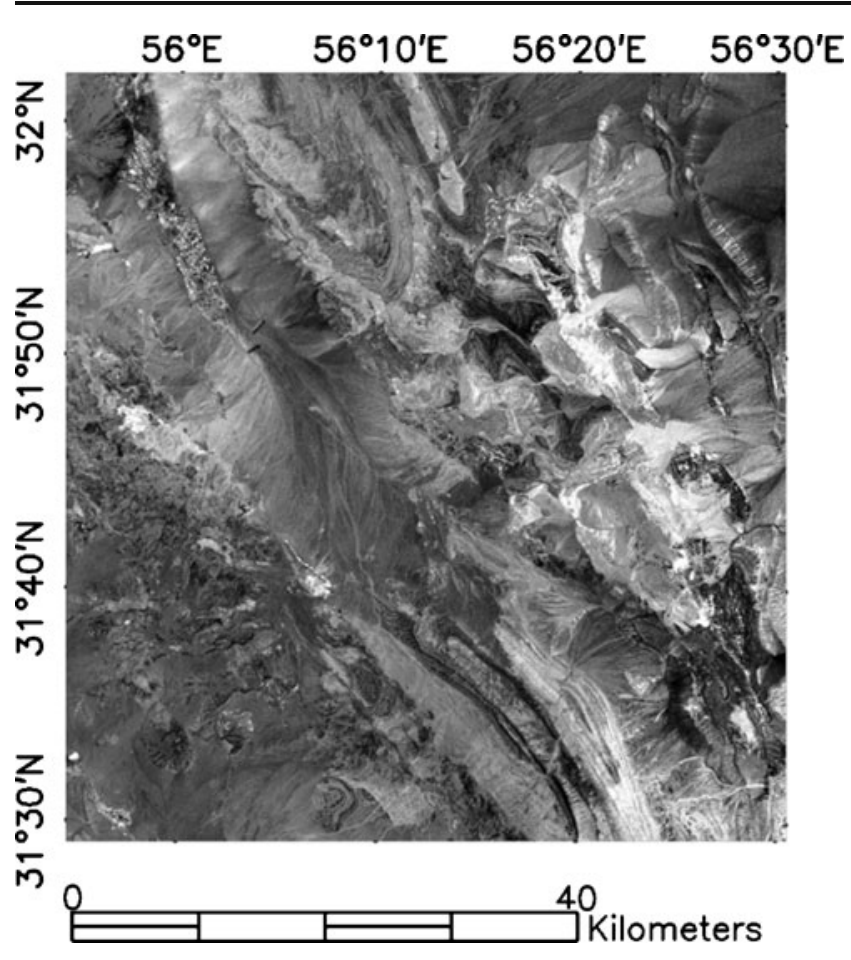

Fig. 1 Ls-Fit image of Behabad area (SWIR-b7 as the modelled band) showing clay alterations as dark pixels

PCA is widely used for mapping of alteration in metallogenic provinces (Abrams et al. 1997; Kaufman 1988; Loughlin 1991; Bennett et al. 1993; Tangestani and Moore 2001).

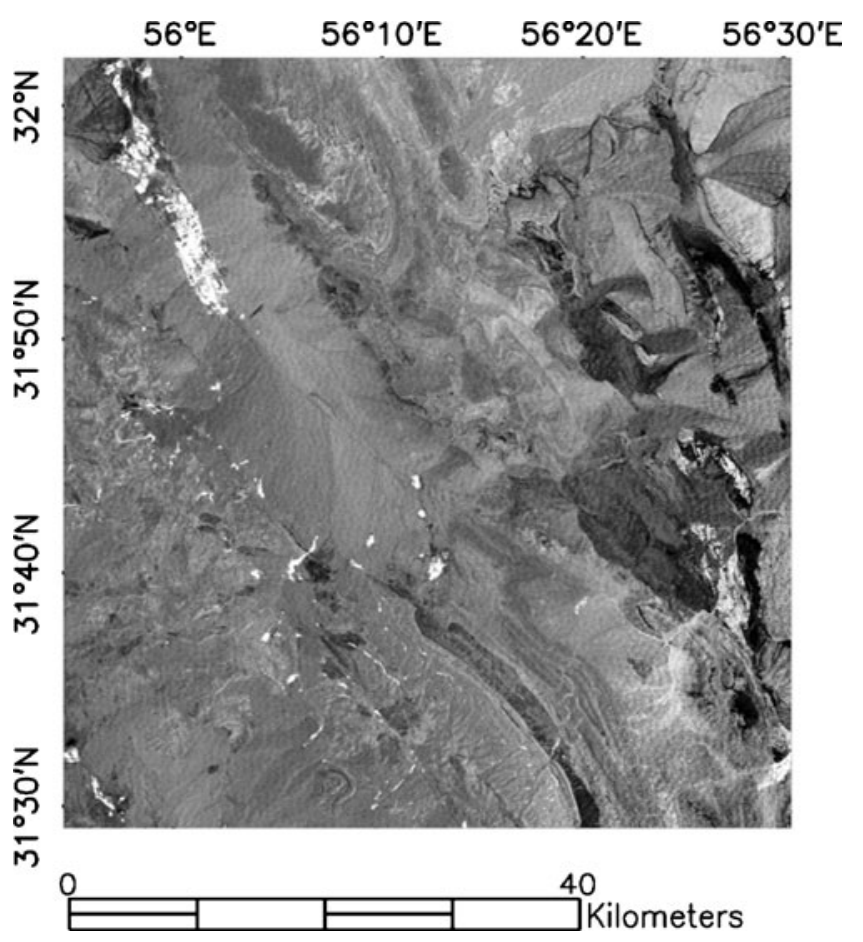

Fig. 2 Ls-Fit image of Behabad area (SWIR-b3 as the modelled band) showing hematite alterations as dark pixels

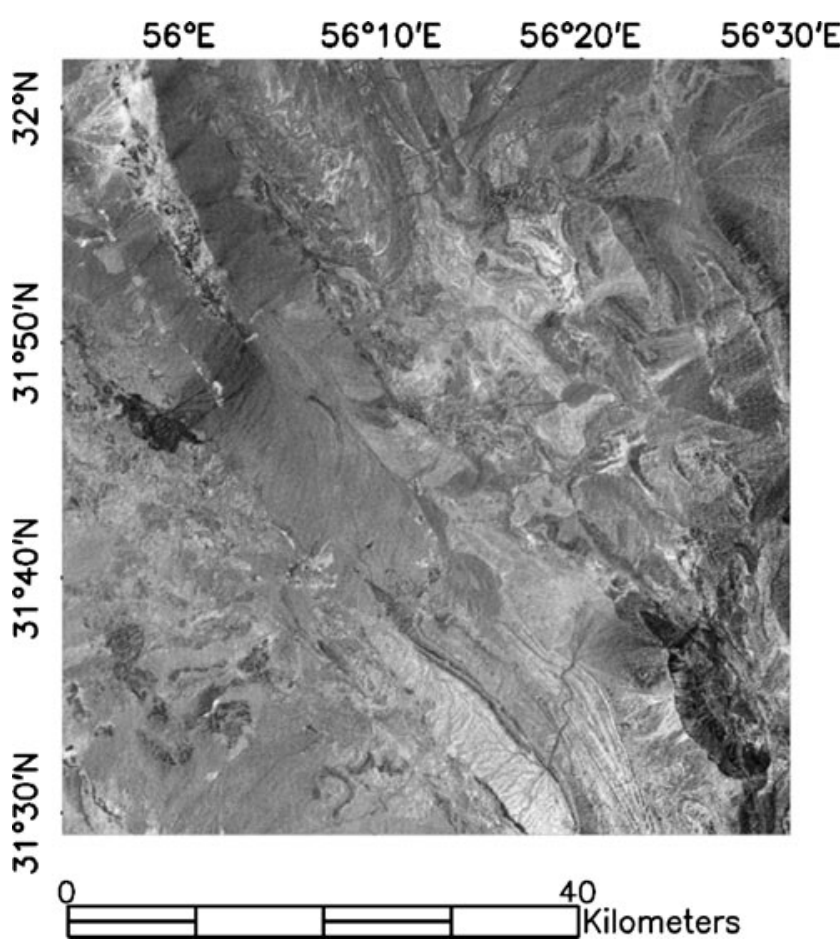

Fig. 3 Ls-Fit image of Behabad area (SWIR-b1 as the modelled band) showing Goethite alterations as dark pixels

Crosta technique is also known as feature oriented principal component selection. Through the analysis of the eigenvector values it allows identification of the principal components that contain spectral information about specific minerals, as well as the contribution of each of the original bands to the components in relation to the spectral response of the materials of interest (Figs. 2 and 3). This technique indicates whether the materials are represented a bright or dark pixels in the principal components according to the magnitude and sign of the eigenvector loadings. This technique can be applied on four

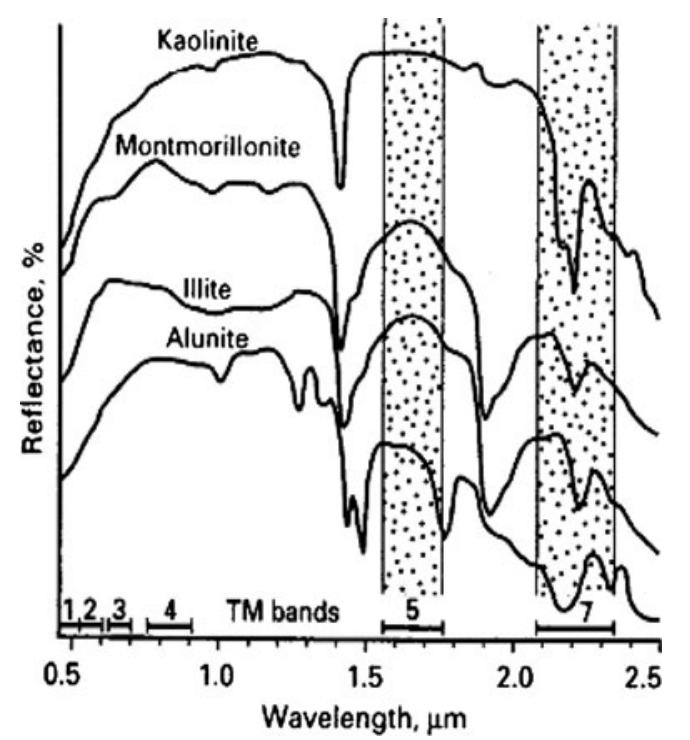

Fig. 4 Reflectance spectra of some common clay 




Fig. 5 Spectral reflectance curves for jarosite, hematite and goetite showing sharp fall off in reflectance in the UV-blue region due to the charge-transfer effect

bands of ETM+ data (Crosta and Moore 1989; R-Armenta and Prol-Ledesma 1998).

Hydroxyl-bearing minerals form the most widespread product of alteration. An abundance of clays and sheet silicates, which contain $\mathrm{Al}-\mathrm{OH}$ and $\mathrm{Mg}-\mathrm{OH}$ bearing minerals and hydroxides in the alteration zones, implies that absorption bands in the 2.1-2.4 $\mu \mathrm{m}$ range (Band7) due to molecular vibration processes becoming very prominent (Fig. 4). At the same time they have a very high reflectance in Band 5; therefore, a ratio of Band5/Band 7 would yield very high values for altered zones comprising dominantly hydroxyl-bearing minerals. This characteristic of phyllosilicates has been used in numerous mineral exploration investigations (Ranjbaran et al. 2004).

Iron oxide is quite a common constituent of alteration zones associated with hydrothermal sulphide deposits. The presence of iron oxide, due to the charge-transfer effect (Fig. 5), leads to strong absorption in the UV-blue region. According to Fig. 5, iron oxide-bearing minerals can be detected by the Band3/Band1 ratio. This ratio would yield very high values for iron oxide-bearing areas. Surface weathering on most of hydrothermal sulphide deposits causes the formation of iron oxide-bearing minerals.

Therefore, this spectral characteristic has been extensively applied in exploration of hydrothermal alterations (Ranjbaran et al. 2004).

Table 1 Eigenvalues calculated for principal components of data for $\mathrm{OH}$ minerals

\begin{tabular}{llllc}
\hline Eigenvector & Band1 & Band4 & Band5 & Band7 \\
\hline Pc1 & 0.470182 & 0.314566 & 0.585715 & 0.580444 \\
pc2 & 0.837168 & 0.120692 & -0.44441 & -0.29511 \\
pc3 & 0.174953 & -0.79529 & -0.23796 & 0.529407 \\
pc4 & 0.217877 & -0.50397 & 0.634678 & -0.54381 \\
\hline
\end{tabular}

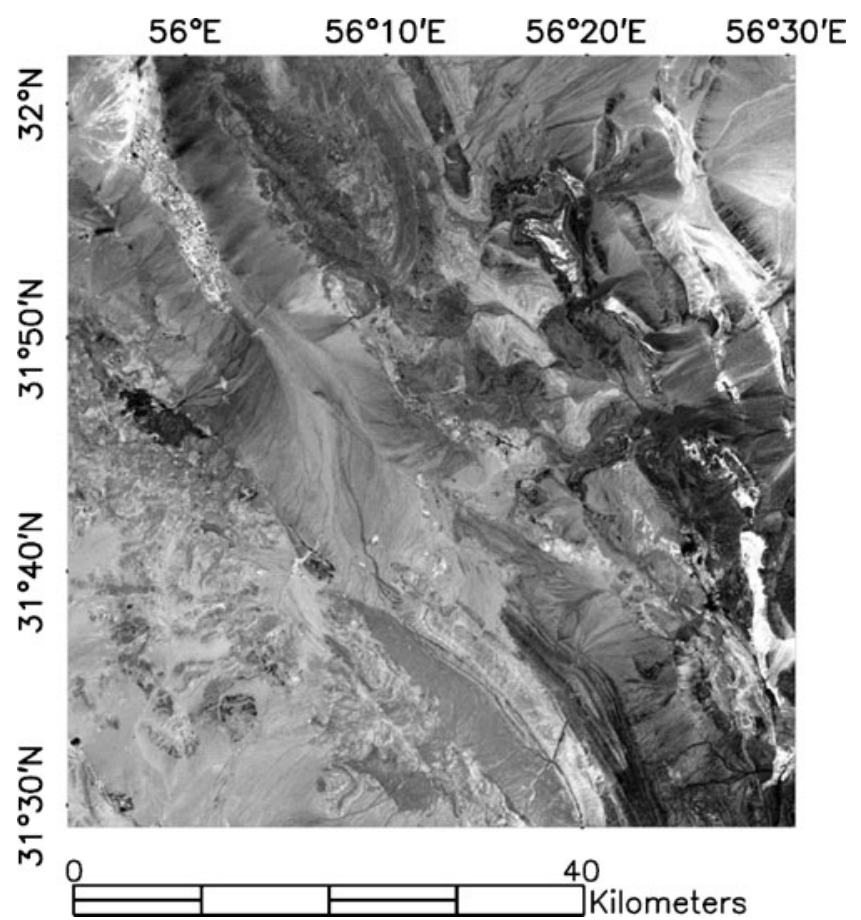

Fig. 6 This image is obtained by using the eigenvector loadings of PC4. The hydroxyl image shows the altered areas in bright pixels

The principal component transformation (eigenvectors and eigenvalues) described in Table 1 , is performed by using four ETM+ bands as input bands (bands 1, 4, 5 and 7). The image of PC4 (Fig. 6), indicates that the clay minerals have absorption in band 7 and Reflection in band 5 . Therefore, it is expected that these bands have higher loadings of through PC analysis, but with opposite sign. PC4 has, then, a negative contribution of band 5 and positive contribution of band 7. Therefore, pixels that have hydroxyl minerals will be darker in the final hydroxyl image. But in order to show the areas with hydroxyl minerals in bright pixels an inverse of this PC is obtained by using PC4.

The same technique is used on 4 Bands (Bands 1, 3, 4 and 5) to enhance iron oxides.

According to reflectance of iron oxides in Fig. 5, these minerals have absorption feature in band 3 and strong reflection in band1. These two bands have, therefore, higher loadings through PC analysis, but again with opposite sign, and the pixels with more abundances of iron oxides minerals will be darker in the final image. In order to

Table 2 Eigenvalues calculated for principal components of data for $\mathrm{Fe}$ oxides minerals

\begin{tabular}{lllll}
\hline Eigenvector & Band1 & Band3 & Band4 & Band5 \\
\hline pc1 & 0.51048 & 0.503134 & 0.338327 & 0.609754 \\
pc2 & 0.649948 & 0.231668 & -0.02125 & -0.7235 \\
pc3 & 0.505303 & -0.46789 & -0.64908 & 0.323184 \\
pc4 & 0.248287 & -0.68867 & 0.681013 & -0.01748 \\
\hline
\end{tabular}




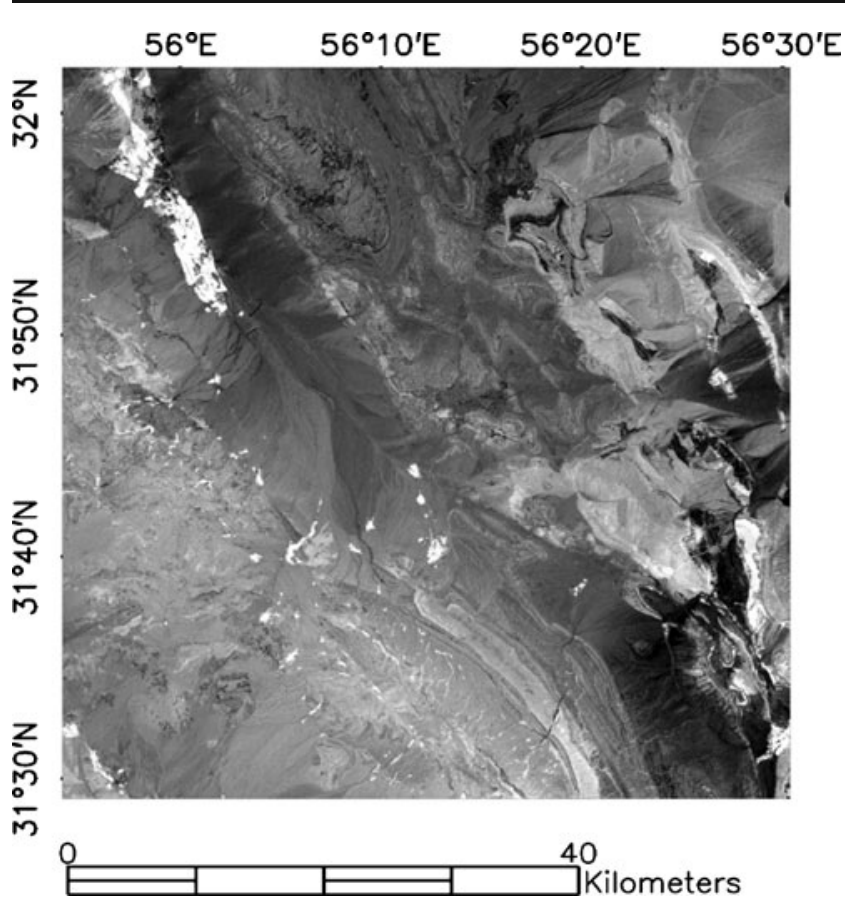

Fig. 7 This image is obtained by using the eigenvector loadings of PC3 to enhance iron oxide. The bright pixels are the areas with iron oxide

show the areas with Iron oxides minerals in bright pixels, an inverse of this PC is obtained by using PC3. The results of principal component analysis are illustrated in Table 2 and Fig. 7 is the image of PC3.

Minimum noise fraction

MNF rotation is used to show the variation between bands in an image. This is a statistical method which works out differences in an image based on pixel DNs in various bands (Kalinowski and Oliver 2004). This is to recognize the differences rather than the similarities between bands. The MNF rotation transforms is used to determine the inherent dimensionality of image to segregate noise in the data as well as to reduce the computational requirements for subsequent processing. The data space can be divided into

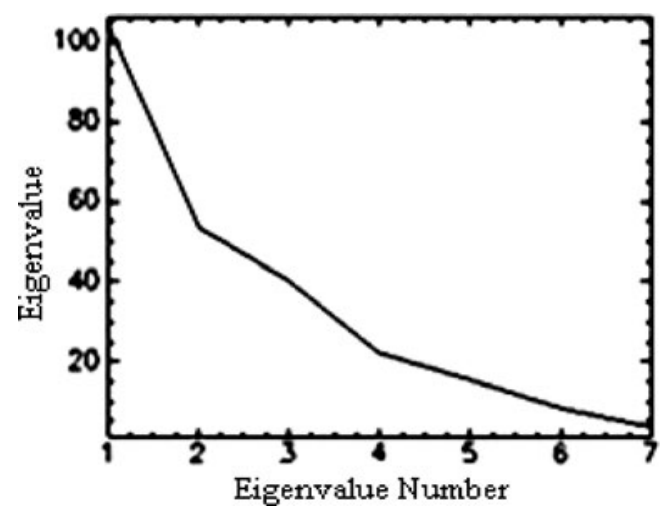

Fig. 8 Noise segregation plot

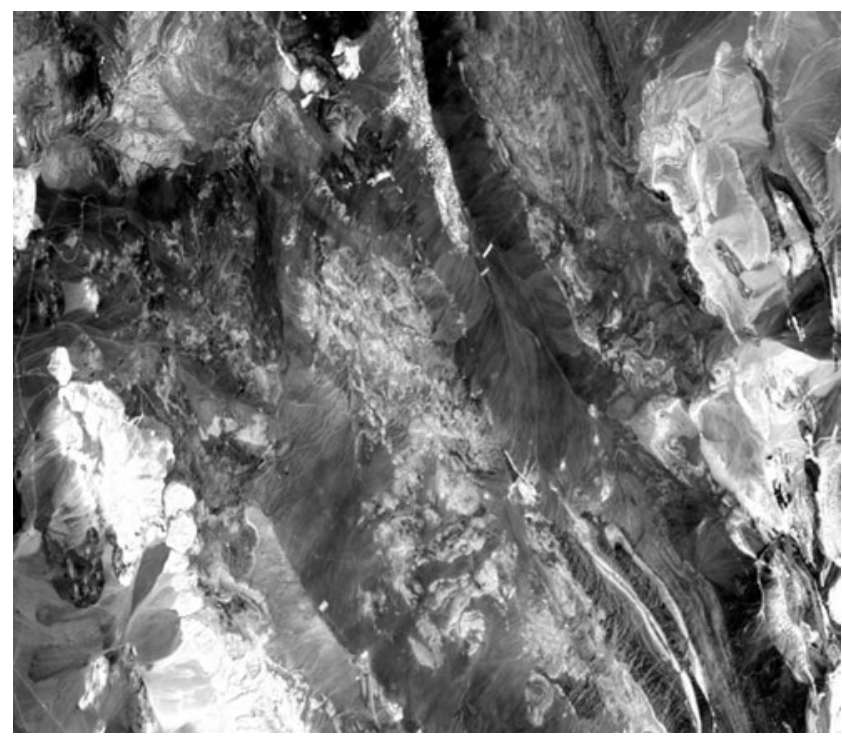

Fig. 9 MNF band 1

two parts: one part associates with large eigenvalues and coherent eigen images, and a complementary part with near-unity eigenvalues and noise-dominated images. By using only the coherent portions, the noise is separated from the data, thus improving spectral processing results.

The MNF eigenvalues decrease sequentially by band as shown in Fig. 8. It illustrates how noise is segregated in the last MNF bands. The decrease in spatial coherency by band in the resultant MNF image is shown in Figs. 9 and 10.

Pixel purity index

The pixel purity index (PPI) function finds the most spectrally pure or "extreme" pixels in multispectral and hyperspectral data. The extreme pixels correspond to the materials with spectra that combine linearly to produce all of the spectra in the image. The PPI was computed by using

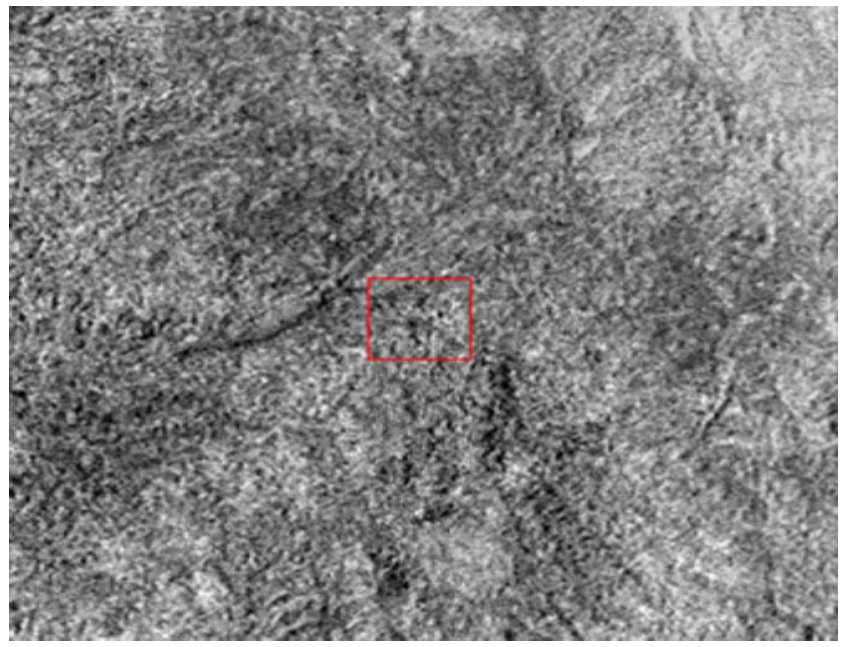

Fig. 10 MNF band 6 


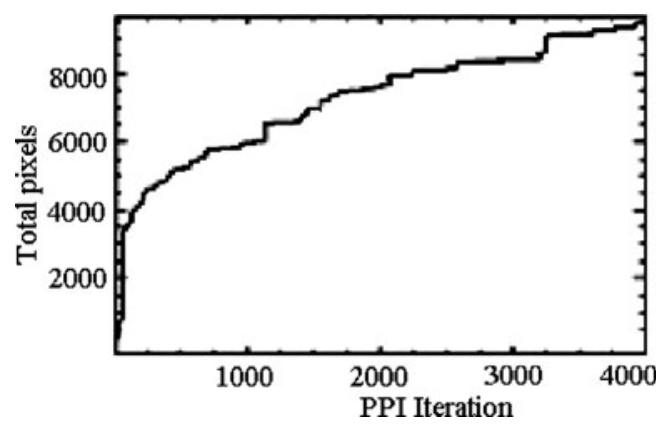

Fig. 11 PPI index

projections of $\mathrm{n}$-dimensional scatter plots to 2-D space and marking the extreme pixels in each projection. The extreme pixels in each projection were recorded and the total number of times each pixel was marked as extreme was noted. The output is an image (the PPI image) in which the $\mathrm{DN}$ of each pixel in the image corresponds to the number of times that pixel was recorded as extreme(Altinbas et al. 2005). Bright pixels in the image, therefore, show the spatial location of spectral endmembers. A threshold is used to select several thousands of pure pixels for further analysis, and then, the number of pixels to be examined decreases significantly (Fig. 11). According to the diagram resulted by the PPI analysis in Fig. 11, the total extreme pixels indicated in the image is equal to 9,553 by 4,000 iterations and threshold of 2.5 .

\section{N-Dimensional visualization and endmember extraction}

The $n$-D visualization was used in conjunction with the MNF and PPI tools to locate, identify, and cluster the purest pixels and the most extreme spectral responses in the data set. If spectral signatures are recorded properly and the curve shape is accurate, they could be used for remote sensing applications(Altinbas et al. 2005). The coordination of the points in $\mathrm{n}-\mathrm{d}$ space consists of " $n$ "values that are simply the spectral radiance or reflectance values in each band for a given pixel. The distributions of these points in n-d space were used to estimate the number of spectral endmembers. Five pure spectral signatures are then extracted and plotted in an n-D
Fig. 12 Classes of the selected spectra. a Hematite, $\mathbf{b}$ epidote, $\mathbf{c}$ jarosite, $\mathbf{d}$ muscovite, $\mathbf{e}$ goethite, f clay
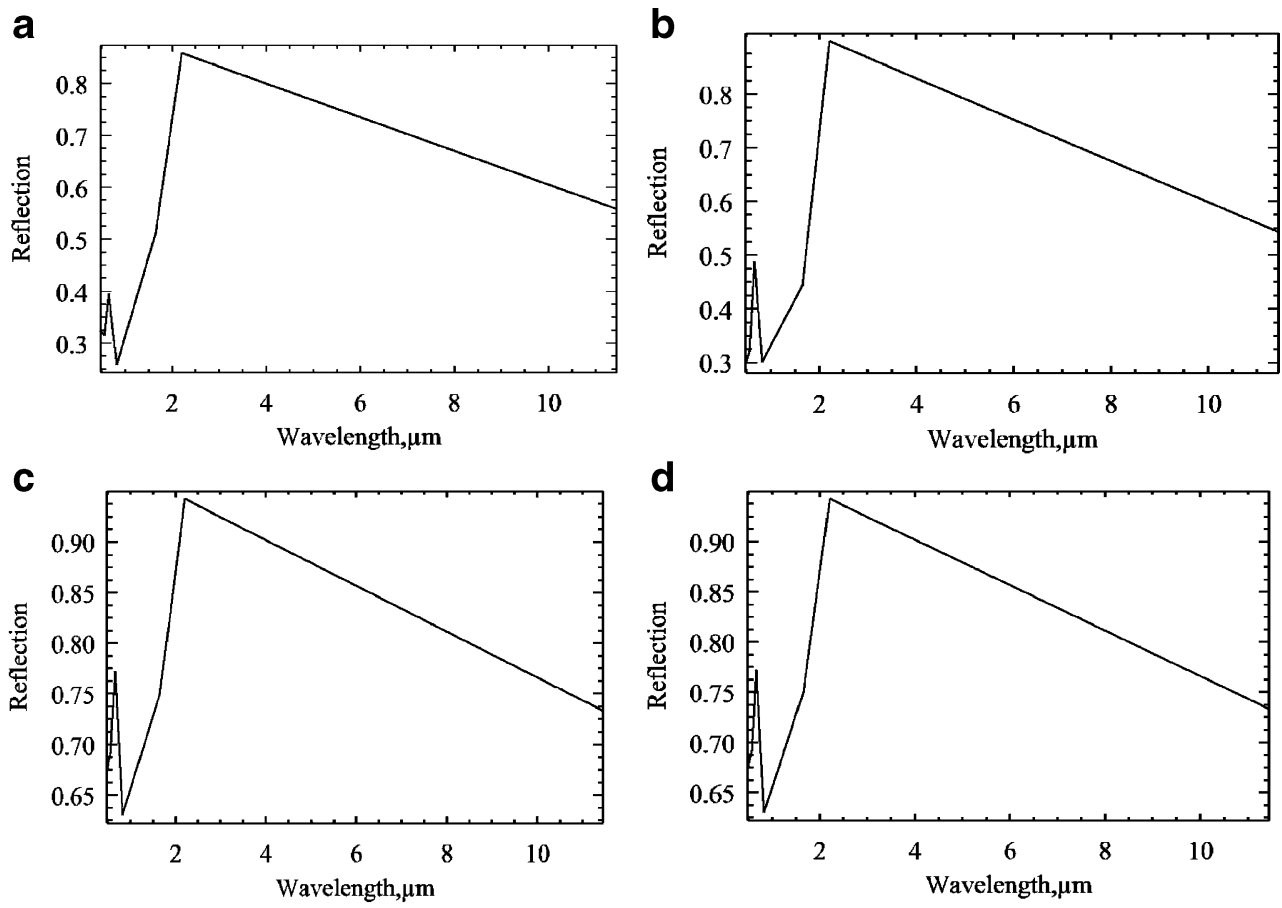

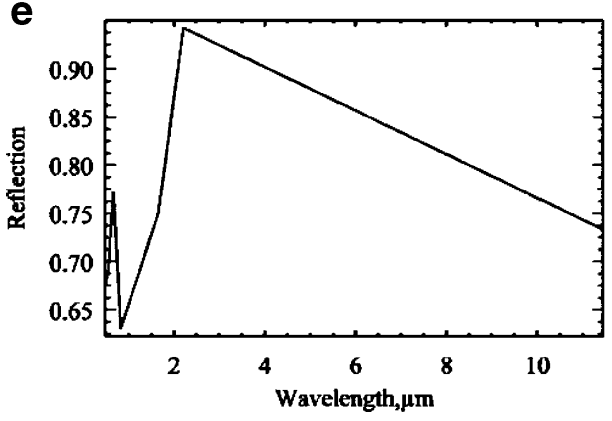


Table 3 Weighting methods and mineral type/score of the extracted spectra

Weighting method (Score $0-1.0)$

\begin{tabular}{|c|c|c|c|c|c|c|}
\hline \multirow{2}{*}{$\begin{array}{l}\text { Spectra } \\
\text { classes }\end{array}$} & \multicolumn{2}{|l|}{ SAM } & \multicolumn{2}{|l|}{ SFF } & \multicolumn{2}{|l|}{$\mathrm{BE}$} \\
\hline & Mineral & Score & Mineral & Score & Mineral & Score \\
\hline 1 & - & 0 & hematite & 0.997 & hematit & 0.899 \\
\hline 2 & - & 0 & Allanite & 0.937 & Allanite & 0.617 \\
\hline 3 & - & 0 & Jarosite & 1 & Jarosite & 0.997 \\
\hline 4 & - & 0 & muscovite & 1 & muscovit & 0.999 \\
\hline 5 & - & 0 & Goethite & 0.993 & Goethit & 0.714 \\
\hline
\end{tabular}

visualizer. The spectral profiles of the selected endmembers are shown in Fig. 12.

\section{Determination of unknown spectra}

Spectral analyses and consequently mineral identification could be obtained by matching the unknown spectra to pre-defined (library) spectra. We used the USGS mineral spectral library as the reference spectra and spectral angle mapper, SFF and binary encoding as matching methods for this comparison. The minerals with highest spectral fitting to the unknown profiles are illustrated in Table 3 along with fitting score $(0.0$ to 1.0$)$ for each method.

\section{Mapping of endmembers}

Determination of abundances of detected minerals in the study scene was performed using matched filtering (MF) unmixing method.

Matched Filtering maximizes the spectral response of a known endmember and suppresses the response of the composite unknown background, and then computes distribution of each endmember separately. This method does not, therefore, require knowledge of all the endmembers within the image. MF results are grey scale images with values from 0 to1, where 1 means perfect match(Adeli et al. 2008). The dataset has been unmixed by MF to produce abundances images of detected alteration minerals.

\section{Data integration}

GIS can easily produce Mineral Potential Maps and integrates the results of different investigations such as geological, geophysical, and geochemical studies. Using a powerful method for weighting of the information, GIS can provide a better prediction on the potential of mineralization under the ground (Hosseinali and Alesheikh 2008).
In this section we integrated all data layer resulted by remote sensing processes in ArcGIS Software in order to determin most possible alteration zones in the study area.

The basic pre-requisite for Mineral Potential Maps generation is the determination of weights and rating values representing the relative importance of factors and their categories (Haroni and Hale 2001).

Determining the relative importance of information is called map layer weighting. In general, each layer of information includes some sub-classes. The importance of sub-classes has to be determined before assigning weights to the layers. This procedure is called calibration and the weights are assigned to the classes are called rating. There are two main methods for weighting the information layers; data-driven and knowledge-driven. In data-driven methods (e.g. Weight of Evidence (WOE)), the importance of data is determined by using data itself while in knowledge-driven methods, an expert or a group of experts perform this task (Hosseinali and Alesheikh 2008).

A set of processes is needed to integrate the input layers properly. The layers were therefore reclassified in the same range (gray scale) and WOE method was used here for weighing each layer and its sub-classes according to their credibility. The factor of Iron oxides is computed by overlaying of $\mathrm{PC} 3$ of the Crosta method and residual band3 and band1 of the LS-Fit method and MFband5 and MFband1 of the rule image of spectral analysis. The $\mathrm{OH}$ bearing minerals were indicated by overlaying of residual

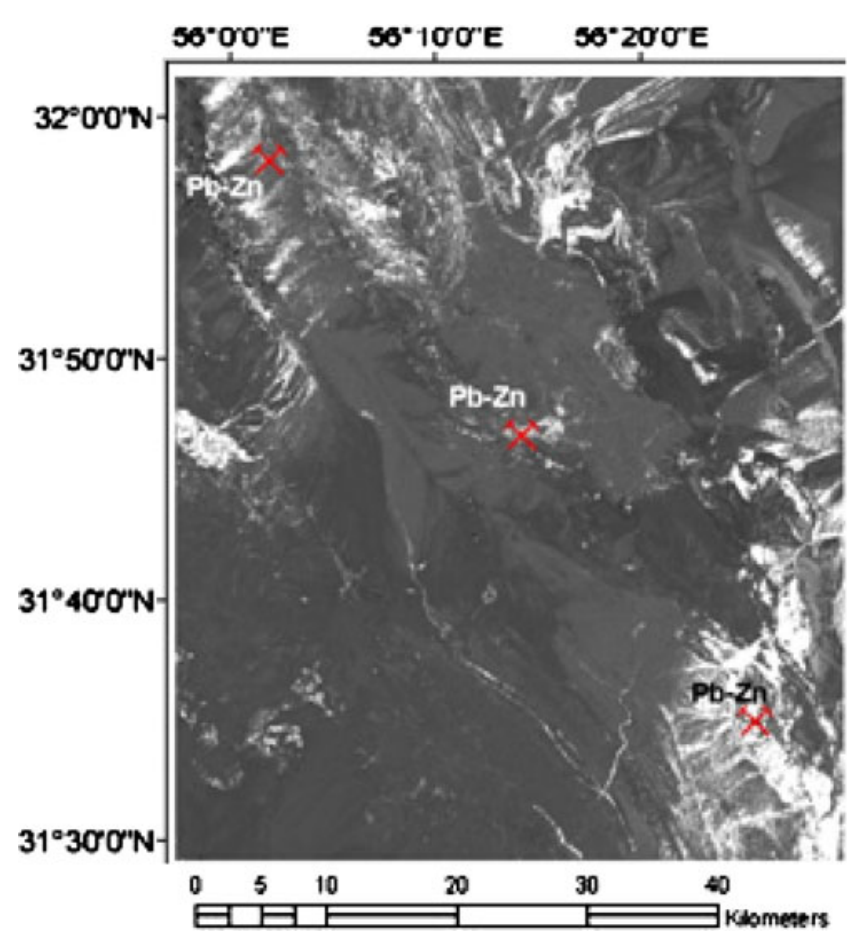

Fig. 13 Results of data integration in a GIS environment, showing the alteration zones and $\mathrm{Pb}-\mathrm{Zn}$ index in Behabad zone 
band7 of LS-Fit and PC4 of the Crosta method and MFband4 of the rule image. MFband2 (epidote) and MFband3 (jarosite) were considered as two other indicative factor, and a potential map was then produced by integration of this four layers. As shown in Fig. 13 the white zones are most possible alterations that coincide to the $\mathrm{Zn}-\mathrm{Pb}$ mineralization recognized previously in the study area. This area, therefore, has suitable potential for new explorationary targets.

\section{Conclusion}

The use of ETM+ in the early stages of mineral exploration was very successful for recognition of the hydrothermal alterations. Detection of hydroxyl and iron oxide minerals implied satisfactory results in the Behabad zone, Iran. In this reaserch, the performance of spectral analysis was investigated for multispectral datasets. According to the results of this study, this method has reliable functionality in the case of ETM data. Additional information, such as Crosta or LS-Fit methods, however, can help better recognition of alterations. In the term of spectral matching methods, SFF has the best accuracy and reliable results. Integrating data layers in ArcGIS improves the accuracy of results by the use of all evidences. In this paper, we applied weight of evidence as a data-driven method, for this prominence is given to each layer, regarding its importance and relation to the study area. The WOE was suitable method for overlaying because the resultant alteration map has a good correlation with the location of the mineralizations in Behabad area according to geological map prepared by Geological Survey of Iran (GSI) (Mahdavi et al. 1996). The locations of three known concentrations are marked on the Fig. 13. These are Kuh-e-Mousa in the northwest, Zaghou in the central part, and Kuh-e-Kamar-e-Saylou in the southeast of the study area that all of them are occurred along the behabad fault that has been identified before (Mahdavi et al. 1996).

Open Access This article is distributed under the terms of the Creative Commons Attribution Noncommercial License which permits any noncommercial use, distribution, and reproduction in any medium, provided the original author(s) and source are credited.

\section{References}

Abrams MJ, Ashley RP, Brown LC, Goetz AFH, Kahle AB (1997) Mapping of hydrothermal alteration in the Cuprite mining district, Nevada, using aircraft scanning images for the spectral region 0.46 to $2.36 \mathrm{~mm}$. Geology 5:713-718
Adeli Z, Rassa I, Darvishzadeh A (2008) Application of matched filtering technique to target alteration minerals. 29th Asian Conference on Remote Sensing(ACRS), srilanka

Altinbas U, Kurucu Y, Bolca M (2005) Using advanced spectral analyses techniques as possible means of identifying clay minerals. Turk J Agric For 29(1):19-28

Bennett SA, Atkinson WW, Kruse FA (1993) Use of Thematic Mapper imagery to identify mineralization in the Santa Teresa district, Sonara, Mexico. Int Geol Rev 35:1009-1029

Crosta A, Moore JMcM (1989) Enhancement of Landsat Thematic Mapper imagery for residual soil mapping in SW Minais Gerais State, Brazil: a prospecting case history in Greenstone belt terrain. In:Proceedings of the Seventh ERIM Thematic Conference: remote Sensing for Exploration Geology. pp 1173-118

Ferrier G, White K, Griffiths G, Bryant R, Stefouli M (2001) The mapping of hydrothermal alteration zones on the island of Lesvos, Greece using an integrated remote sensing dataset. Int J Rem Sens 23:341-356

Haroni HA, Hale M (2001) A Predictive GIS Model for Mapping Potential Gold and Base Metal Mineralization in Takab Area, Iran. Comput and Geosci 27(8):901-912

Haroni H A, Lavafan A (2007) Integrated analysis of Aster and Landsat Etm data to map exploration targets In The Muteh GoldMining Area, Iran. Available at: http://www.itc.nl/issdq. Accessed 20 June 2009

Hosseinali F, Alesheikh AA (2008) Weighting Spatial Information in GIS for Copper Mining Exploration. Am J Appl Sci 5(9):1187-1198

Islam NE, Salim B, Ahmed K, Belbachir H (2004) Multispectral analysis of satellite images. Available at: http://www.isprs.org/ congresses/Istanbul. Accessed 12 July 2009

Kalinowski A, Oliver S (2004) ASTER Mineral Index Processing Manual. Remote Sensing Applications Geoscience, Australia

Karnieli A, Ben-Dor E, Bayarjargal Y, Lugas R (2004) Radiometric saturation of Landsat-7 ETM+data over the Negev Desert: problems and solutions. Int J Appl Earth Obs Geoinf 5:219-237

Kaufman H (1988) Mineral exploration along the Agaba-Levant structure by use of TM-data concepts, processing and results. Int J Remote Sens 9:1630-1658

Loughlin WP (1991) Principal component analysis for alteration mapping. J Photogramm Eng Rem Sens 57:1163-1169

Mahdavi MA, Sahabaei M, Mirtohidi I, Haddadan M, Gomashi A (1996) Geological map of Behabad, Geological Survey of Iran (GSI)

Markham BL, Dabney PW, Storey JC, Morfitt R, Knight EJ, Kvaran G, Lee K (2008) Landsat Data Continuity Mission Calibration And Validation. ASPRS Publications, Colorado, USA

Oskouei MM, Busch W (2008) A geostatistically based preprocessing algorithm for hyperspectral data analysis. GIScience and Remote Sensing 45(3):356-368

Ranjbaran H, Honarmandb M, Moezifar Z (2004) Application of the Crosta technique for porphyry copperalteration mapping, using ETM data in the southern part of the Iranian volcanic sedimentary belt. J Asian Earth Sci 24:237-243

R-Armenta JR, Prol-Ledesma RM (1998) Techniques for enhancing the spectral response of hydrothermal alteration minerals in Thematic Mapper images of Central Mexico. Int J Rem Sens 19:1981-2000

Rencz AN (1999) Remote Sensing For The Earth Sciences. Wiley, USA

Singh A, Harrison A (1985) Standardized principal components. Int J Remote Sens 6:883-896

Tangestani MH, Moore F (2001) Comparison of three principal component analysis techniques to porphyry copper alteration mapping: a case study, Meiduk area, Kerman, Iran. Can J Remote Sens 27:176-181

Yetkin E, Toprak V, Suezen ML (2004) Alteration Mapping By Remote Sensing: Application To Hasandağ-Melendiz Volcanic Complex. Available at: http://www.isprs.org/congresses/istanbul. Accessed 14 June 2009 